\title{
Lower limb laterality versus foot structure in men and women
}

\author{
Lidia IInicka ${ }^{1}$ Zbigniew Trzaskoma $^{2}$, Ida Wiszomirska ${ }^{1}$, Andrzej Wit $^{1}$, Michał Wychowański $^{1}$ \\ ${ }^{1}$ Chair for the Biological Foundations of Rehabilitation, Faculty of Rehabilitation, Academy of Physical Education, \\ Warsaw, ${ }^{2}$ Chair of Physiotherapy, Faculty of Rehabilitation, Academy of Physical Education, Warsaw
}

\begin{abstract}
Study aim: The aim of the study was to determine connections between the functional asymmetry of limbs and the morphological asymmetry of feet.

Material and methods: The study population consisted of 56 students: 30 females (mean age $20.29 \pm 0.59$ years) and 26 males (mean age $20.41 \pm 0.78$ years). The measurements of body build were taken with classical instruments. Body build was assessed on the basis of body height, body mass, and BMI. Seven features of the foot and 8 indices of foot arches were assessed. Assessment of laterality in upper and lower limbs was conducted on the basis of data from repeated interviews, and then verified with simple motor tests that imitated characteristic functions of the limbs. Asymmetry indices were calculated in order to determine asymmetries of the features. Mollison's index was applied to assess dimorphic differences.

Results: Features that were statistically different in the foot of the dominant limb and in the foot of the non-dominant limb were: among the group of females, the foot length without hindfoot, and the Clarke's angle; among the group of males - the foot length without toes. Analyses of results of this study do not allow for a claim that laterality of lower extremities has a considerable impact on indices of longitudinal and transverse foot arches.

Conclusions: The following conclusions were formulated on the basis of the conducted analysis regarding the group of subjects with homogeneous right laterality:

- in females, the dominant limb's foot is characterized by a shorter bone arm lever for dorsiflexors;

- in males, the dominant limb's foot is characterized by a shorter bone arm lever for plantaflexors.
\end{abstract}

Key words: Lower limbs - Laterality - Morphological asymmetry - Functional asymmetry - Sexual dimorphism

\section{Introduction}

In the course of human phylogenesis, lower limbs have adapted to serve the supporting and locomotion functions. Because of its topography in the pionised human body, the foot is an extremely important element of the human locomotor system. It is the first element of the system that remains in contact with the ground, and it forms a strong and springy structure, well adapted to bearing the body's weight. The foot serves the absorptive function due to its unique structure of the longitudinal and transverse arches. On the basis of available literature, one can state that the height of foot arches, especially the longitudinal arch, is identified with the foot's correct function [25, 27].

A distinct issue related to human motor abilities an issue discussed by numerous authors - is lateral preference, also referred to as laterality or functional dominance, asymmetries of the body, footedness-handedness, bilateral dominance, and sidedness. The following kinds of laterality can be found: homogeneous laterality, i.e., one side of the body clearly dominates over the other (e.g., right-handedness and right-footedness, or left-handedness and left-footedness); and mixed laterality (or cross-dominance), i.e., there is no distinctive dominance on one side of the body over the other (e.g. right-footedness along with left-handedness). According to contemporary theories, lateral functional dominance (functional asymmetry) develops and consolidates as a result of the influence of endogenic and exogenic factors $[2,18,29]$. Asymmetry can be examined from several aspects: morphological, functional, dynamic (motor), sensory, and psychological. The manifestations of functional asymmetry in motor activities are not only handedness (right-handedness or left-handedness), but 
also footedness (right-footedness or left-footedness). When referring to studies by numerous authors and to her own results, Olex-Zarychta [16] stresses that the phenomenon of limb functional asymmetry is important in all motor performance and impacts its course and end effect. The functional asymmetry of the lower extremities is established both on the basis of observation conducted while subjects perform various tasks as well as on the basis of surveys. As a result of functional asymmetry, signs of morphological asymmetry may gradually intensify with age, i.e., discrepancies in sizes (perimeters, lengths, widths), shapes, and proportions of paired organs. Dynamic asymmetries are the differences in performance of, for example, right and left limbs with respect to strength, speed, and endurance (these can be determined in psychomotoric tests and measurements). The term, therefore, relates to quantitative differences (not just functional differences) of a given property. Functional dominance of the right side of the body is observed in most (approximately 90\%) people. It is related to the dominance of the left brain hemisphere, which typically regulates the functions of the right upper limb, right lower limb, and right eye. Human body laterality has long been the subject of interdisciplinary studies. Numerous studies have been conducted concerning morphological and functional manifestations of laterality $[15,16,27]$. However, the number of studies that investigate the many sides of the matter on the same material, i.e., discussing the combined aspects of upper and lower limb dominance as well as morphological and functional asymmetries, all in the context of dimorphic differences, is limited.
The aim of the study was to determine the relations between the functional asymmetry of limbs and the morphological asymmetry of feet. The main aim of the author was to assess the differences between the foot size and foot indices in men and women as well as to assess the connections of these variables with the laterality of upper and lower limbs.

\section{Material and methods}

This cross-sectional study was conducted in 98 first - and second-year students at the Faculty of Rehabilitation at the University for Physical Education in Warsaw. When highly qualified athletes, subjects who had a history of lower limb injuries, and subjects on whom data was incomplete were excluded from the study, the study population eventually consisted of 56 subjects, 30 females (mean age of $20.29 \pm 0.59$ years) and 26 males (mean age of $20.41 \pm 0.78$ years). Consent to conduct the study was obtained from the Ethics Commission.

The measurements of body build were taken with classical instruments and according to standards accepted in anthropometry. General body build was assessed on the basis of body height and mass, and their derivative, i.e., BMI, according to norms of the World Health Organization [26]. The following foot features were measured (Figure 1): foot length with and without toes, foot width, foot height to the sphyrion mediale point and laterale point, foot height to the naviculare point, hindfoot length, plantographic Clarke's angle index for longitudinal arch, podometric index for

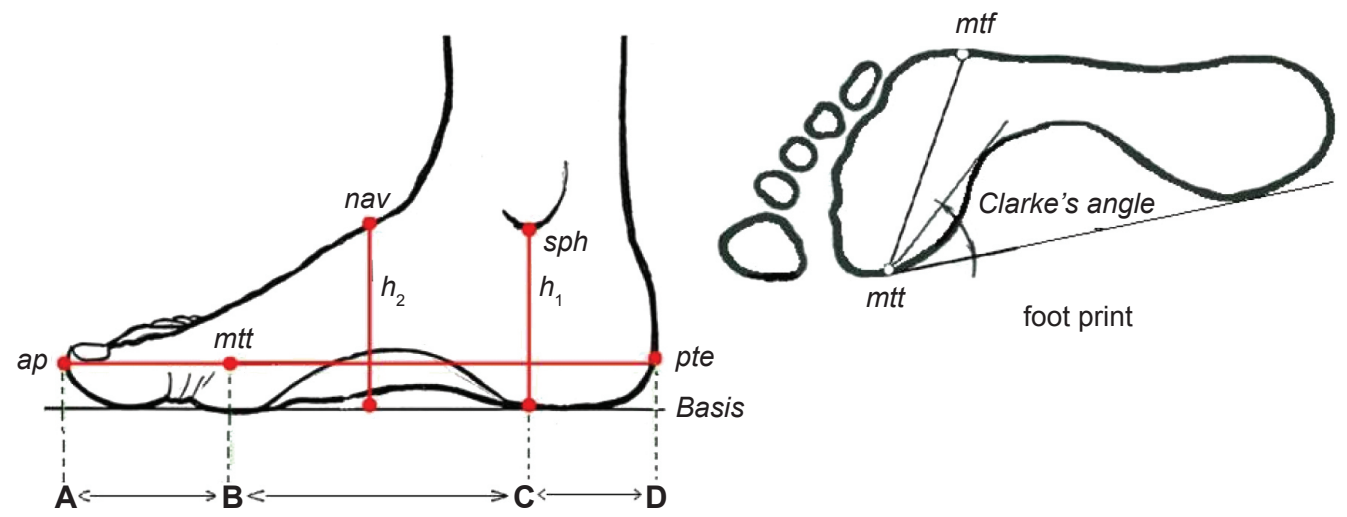

Fig. 1. Points and measurement segments of the foot

akropodion (ap) at the front of the tip of the longest toe; metatarsale tibiale ( $m t t)$ at the centre of the head of the first metatarsal bone; naviculare (nav) on the dorsal surface of the navicular bone; pternion (pte) at the furthest end of the calcanean tuber; sphyrion (sph) at the lowest point of the medial malleous (sphyrion mediale) or of the lateral malleolus (sphyrion laterale); metatarsale fibulare (mtf) at the outer side of the fifth metatarsal bone; $h_{1}$ - the foot height measured from the ground (basis) to the sphyrion point; $h_{2}-$ the foot height measured form the ground (basis) to the naviculare point; Clarke's angle - longitudinal arch angle on the foot print;

A-D foot length [ap-pte]; A-B hallux length, [ap-mtt]; B-D foot length without toes [mtt-pte], C-D hindfoot length, i.e., the distance between the projection of sphyrion and pternion points onto the basis; A-C forefoot length with toes, i.e., the distance between the projection of akropodion and sphyrion points onto the basis; B-C forefoot length without toes, i.e., the distance between the projection of metatarsale tibiale and sphyrion points onto the basis. 
transversal arch, four variants of podometric index for longitudinal arch, and two hindfoot indices.

On the basis of abovementioned measurements, 7 podometric indices were calculated:

$\mathrm{WD}_{1}$ - longitudinal arch index (height of sphyrion mediale /foot length $\mathrm{x}$ 100)

$\mathrm{WD}_{2}$ - longitudinal arch index (height of naviculare /foot length $\mathrm{x} 100$ )

$\mathrm{WD}_{3}$ - longitudinal arch index (height of sphyrion mediale /foot length without toes x 100)

$\mathrm{WD}_{4}$ - longitudinal arch index (height of naviculare/ foot length without toes $\mathrm{x} 100$ )

$\mathrm{WT}_{1}$ - hindfoot index (hindfoot length /foot length $\mathrm{x} 100)$

$\mathrm{WT}_{2}$ - hindfoot index (hindfoot length/ foot length without toes $\mathrm{x} 100$ )

WS - transversal arch's Wejsflog index (foot length/ foot width).

The measurements of longitudinal arches were supplemented with the plantographic method on the basis of the Clarke's angle mapped on a computer foot image. The images were obtained from a POSMED podoscope equipped with a camera. The assessments of laterality for upper and lower limbs were conducted on the basis of data from interviews repeated following a one-week interval, and then verified with simple motor tests that imitated characteristic function of the limbs. The questionnaire consisted of questions on subjects' own limb preference, i.e., on right - or left-handedness in activities such as writing, eating, using scissors, brushing one's teeth, doing one's hair, lighting a match, hammering a nail, slicing bread; and on right - or left-footedness in a vertical jump (the vertical jump test - which limb leads (counter-movement limb), and which is the propulsive limb, takeoff limb), and in kicking a ball (the ball kicking test - which limb kicks a ball, and which limb lends support, maintains posture). When assessing footedness, we assumed, as did Peters [19], Gabbard et al. [8] and Chapman et al. [3], that the mobilizing or leading limb (initiation limb) would be considered the preferred (dominant) limb, and the limb used for support or propulsion, would be considered the non-preferred limb. On the basis of subject answers and tests conducted, we determined the functional asymmetry of limbs. Then, using letters, we established the symbol of a given asymmetry. The symbol informs which limb is preferred in a given activity (limb preference, limb domination). In the symbols, the first letter applies to the upper limb, and the second letter applies to the lower limb. For homogeneous laterality, we used the following symbols:

- $\mathrm{R}_{\text {hand }} \mathrm{R}_{\text {foot }}$ type, right-handedness - right-footedness [R-R symbol];
- $\mathrm{L}_{\text {hand }} \mathrm{L}_{\text {foot }}$ type, left-handedness - left-footedness [L-L symbol];

For cross laterality (cross dominance, mixed laterality), we used the following symbols:

$-\mathrm{R}_{\text {hand }} \mathrm{L}_{\text {foot }}$ type, right-handedness - left-footedness [R-L symbol];

$-\mathrm{L}_{\text {hand }} \mathrm{R}_{\text {foot }}$ type, left-handedness - right-footedness [L-R symbol];

In determining the footedness of the subjects, the results of the vertical jump tests and the ball kick tests did not coincide. Therefore, in the ensuing analysis, we introduced three variants of classification, i.e., variant I with the vertical jump test; variant II with the ball kick test; while variant III was the combination of both variants I and II. In variant III, we introduced the following symbols for denoting the type of functional asymmetry: R-RR and L-LL for homogenous asymmetries; R-LR, R-RL, R-LL, L-LR, L-RR, L-RR for cross (mixed) asymmetries. The fist letter in the symbols denoted the upper limb preferred in activities such as eating, writing, brushing one's hair. The second letter denoted the lower limb preferred for leading (counter-movement limb) in the vertical jump test. The third letter denoted the lower limb preferred for kicking a ball. For example, the R-LR symbol means that the subject was righthanded and left-footed in jumping (left limb led), and right-footed in kicking a ball (left limb kicked a ball).

In order to compare the asymmetries of various features, the following asymmetry indices were calculated [17]:

$$
W_{s k_{\text {asym }}}=\frac{R-L}{(R+L) / 2} \times 100
$$

where: $R$ denotes the value for right limb, $L$ denotes the value for left limb.

Negative values of asymmetry index point to the dominance of the left limb in a given feature. The absolute value of the index determines the degree of diversity - the greater the value, the greater the diversity.

To assess the dimorphic differences, Mollison's index [14] was applied:

$$
W_{s k_{. d m f}}=\frac{\bar{x}_{F}-\bar{x}_{M}}{S D_{M}}
$$

where $: \bar{x}_{F}$ arithmetic mean of the feature in the group of females, $\bar{x}_{M}$ - arithmetic mean of the feature in the group of males, $S D_{M}$ - standard deviation of the feature in the group of males.

Negative values of the index point to the dominance of the feature in men. The absolute value of the index determines the degree of diversity - the greater the value, the greater the diversity.

We put the test results through a detailed statistical analysis. We applied the relevant procedures of the 
Statistica 8.0 programme by StatSoft. On the basis of the arithmetic means of chosen features and indices, we analysed the differences between right and left feet separately in the women's group and in the men's group: the $t$-test for dependent variables and the Wilcoxon signed-rank test for divergent variances of the compared features. In addition, we carried out analyses of differences between sexes and of differences for the chosen types of laterality. The $t$-test was conducted for dependent variables. When the distribution of the compared feature was at variance with the normal distribution in the Shapiro-Wilk test, we carried out the Mann-Whitney U-test. For all the tests, the statistical significance was set at $\mathrm{p} \leq 0.05$.

\section{Results}

In assessing footedness based on the leading limb during a vertical jump, most right-handed subjects indicated the right lower limb as the preferred limb (ipsilateral asymmetry, homogeneous laterality, variant I - the R-R type, right-handed - right-footed) (60.0\% of the women, $65.4 \%$ of the men). Approximately $37 \%$

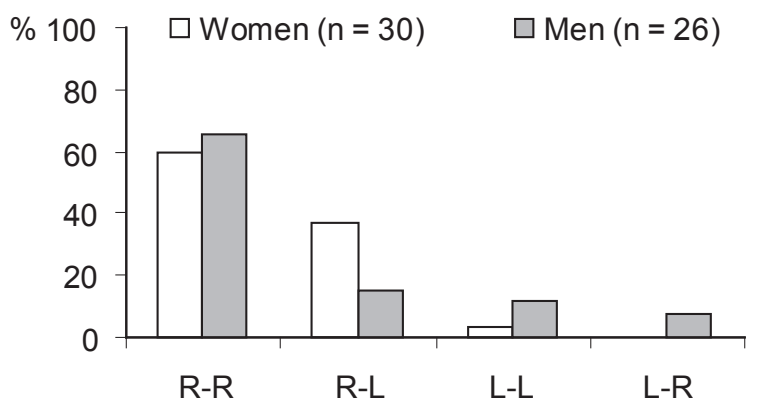

Fig. 2. Classification of subjects (\%) according to the limb laterality type - variant I, upper limb - eating, writing (the first letter in the formula), lower limb - leading limb during vertical jump (the second letter in the formula) of the women and approximately $15 \%$ of the men indicated the left lower limb (contralateral asymmetry, mixed laterality, variant I, R-L type; right-handed left-footed) (Figure 2).

In variant I (assessment of footedness based on the leading limb during a vertical jump), we observed a higher percentage of men (approximately 15\%) than women (approximately 3\%) of ipsilateral left-sided asymmetry (the L-L type). Contralateral asymmetry, i.e., left-handed - right-footed (the L-R type), was observed in approximately $7 \%$ of men; it was not observed in women.

In assessing footedness based on the limb kicking a ball (variant II) (Figure 3), the percentage of men of the R-R and the R-L types was the same as in variant I (65.4\% and $15.4 \%$, respectively); for women, the difference in percentage between the variant I and variant II was $25 \%$ (the R-R type $86.7 \%$, the R-L type $10 \%$ ).

Variant III provided a combined assessment of both tests for lower limbs, i.e., the vertical jump and kicking a ball. Classification of subjects according to their limb preference in variant III (Figure 4) revealed that among the right-handed subjects, considerably fewer subjects,

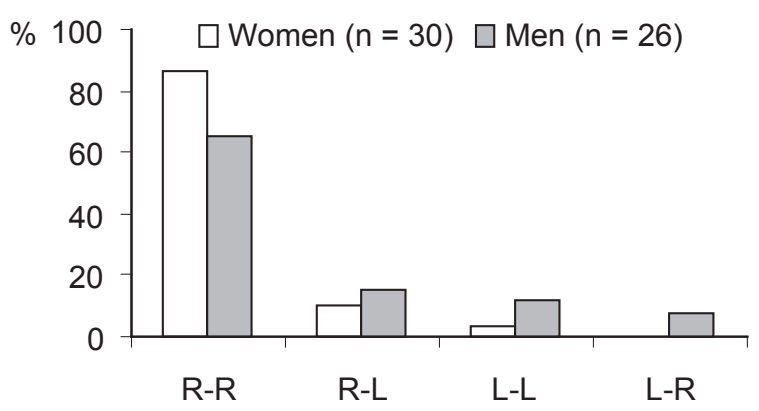

Fig. 3. Classification of subjects (\%) according to the limb laterality type - variant II, upper limb - eating, writing (the first letter in the formula), lower limb - kicking a ball (the second letter in the formula)

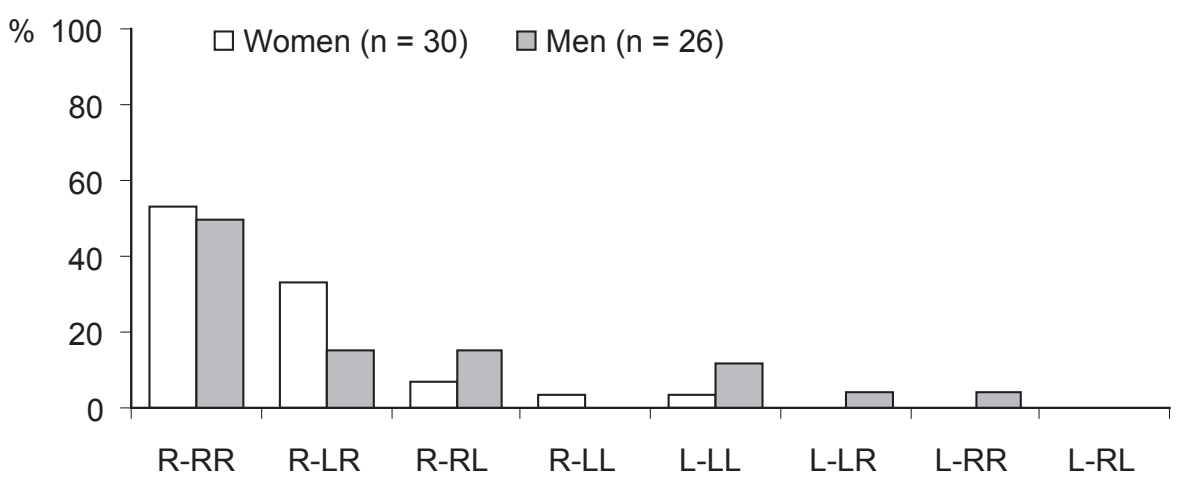

Fig. 4. Classification of subjects (\%) according to the limb laterality type - variant III, upper limb - eating, writing (the first letter in the formula), lower limb - leading limb during vertical jump (the second letter in the formula), lower limb - kicking a ball (the third letter in the formula) 
Table 1. Arithmetic means $( \pm S D)$ of body mass, height, and BMI for both groups for all analysed variants of homogeneous right laterality.

\begin{tabular}{|c|c|c|c|c|}
\hline Variables & Laterality variant & Type & $\begin{array}{c}\text { Women }(\bar{x} \pm S D) \\
\text { I R-R } \mathrm{n}=18 \\
\text { II R-R } \mathrm{n}=26 \\
\text { III R-RR } \mathrm{n}=16\end{array}$ & $\begin{array}{c}\text { Men }(\bar{x} \pm S D) \\
\text { I R-R } \mathrm{n}=17 \\
\text { II R-R } \mathrm{n}=17 \\
\text { III R-RR } \mathrm{n}=13\end{array}$ \\
\hline \multirow{3}{*}{ Body heigth $(\mathrm{cm})$} & I & R-R & $165.17 \pm 5.57$ & $180.12 \pm 6.79$ \\
\hline & II & $\mathrm{R}-\mathrm{R}$ & $165.70 \pm 5.01$ & $181.88 \pm 6.32$ \\
\hline & III & R-RR & $164.94 \pm 5.48$ & $180.69 \pm 6.02$ \\
\hline \multirow{3}{*}{ Body mass $\quad(\mathrm{kg})$} & I & $\mathrm{R}-\mathrm{R}$ & $57.89 \pm 4.39$ & $78.88 \pm 8.68$ \\
\hline & II & $\mathrm{R}-\mathrm{R}$ & $58.42 \pm 4.77$ & $79.18 \pm 7.83$ \\
\hline & III & R-RR & $58.00 \pm 4.61$ & $78.39 \pm 7.81$ \\
\hline \multirow{3}{*}{ BMI } & I & $\mathrm{R}-\mathrm{R}$ & $21.27 \pm 1.85$ & $24.36 \pm 2.82$ \\
\hline & II & $\mathrm{R}-\mathrm{R}$ & $21.30 \pm 1.76$ & $23.92 \pm 1.89$ \\
\hline & III & R-RR & $21.37 \pm 1.93$ & $24.01 \pm 2.11$ \\
\hline
\end{tabular}

Variant I type R-R: Upper limb, eating, writing etc. (the first letter in the formula); Lower limb, in the vertical jump test - leading (the second letter in the formula).

Variant II type R-R: Upper limb, eating, writing etc. (the first letter in the formula); Lower limb, in the ball kick test - the limb kicking a ball (the second letter in the formula).

Variant III type R-RR: Upper limb, eating, writing etc. (the first letter in the formula); Lower limb, in the vertical jump test - leading (the second letter in the formula), Lower limb, in the ball kick test - the limb kicking a ball (the third letter in the formula).

Table 2. Arithmetic means $( \pm$ SD) of chosen traits for right and left feet for all analysed variants of homogeneous right laterality.

\begin{tabular}{|c|c|c|c|c|c|c|}
\hline \multirow[t]{2}{*}{ Traits } & \multirow[t]{2}{*}{$\begin{array}{c}\text { Laterality } \\
\text { variant }\end{array}$} & \multirow[t]{2}{*}{ Type } & \multicolumn{2}{|c|}{$\begin{array}{c}\text { Women } \\
\text { I R-R } \mathrm{n}=18 \\
\text { II R-R } \mathrm{n}=26 \\
\text { III R-RR } \mathrm{n}=16\end{array}$} & \multicolumn{2}{|c|}{$\begin{array}{c}\text { Men } \\
\text { I R-R } \mathrm{n}=17 \\
\text { II R-R } \mathrm{n}=17 \\
\text { III R-RR } \mathrm{n}=13\end{array}$} \\
\hline & & & $\begin{array}{c}\text { Right side } \\
(\bar{x} \pm \mathrm{SD})\end{array}$ & $\begin{array}{l}\text { Left side } \\
(\bar{x} \pm \mathrm{SD})\end{array}$ & $\begin{array}{c}\text { Right side } \\
(\bar{x} \pm \mathrm{SD})\end{array}$ & $\begin{array}{l}\text { Left side } \\
(\bar{x} \pm \mathrm{SD}) \\
\end{array}$ \\
\hline \multirow{3}{*}{ Foot length $(\mathrm{cm})$} & I & $\mathrm{R}-\mathrm{R}$ & $24.65 \pm 0.86$ & $24.78 \pm 0.85$ & $27.24 \pm 1.20$ & $27.36 \pm 1.28$ \\
\hline & II & R-R & $24.63 \pm 0.74^{* *}$ & $24.82 \pm 0.78^{* *}$ & $27.57 \pm 1.37$ & $27.68 \pm 1.41$ \\
\hline & III & R-RR & $24.55 \pm 0.79$ & $24.71 \pm 0.82$ & $27.28 \pm 1.23$ & $27.38 \pm 1.24$ \\
\hline \multirow{3}{*}{$\begin{array}{l}\text { Foot length without toes }(\mathrm{cm}) \\
\text { (arm lever for plantaflexors } \\
\text { - version I) }\end{array}$} & I & R-R & $18.73 \pm 0.63$ & $18.64 \pm 0.63$ & $20.59 \pm 0.92$ & $20.85 \pm 1.21$ \\
\hline & II & R-R & $18.67 \pm 0.64$ & $18.70 \pm 0.63$ & $20.84 \pm 1.02$ & $21.06 \pm 1.07$ \\
\hline & III & R-RR & $18.66 \pm 0.59$ & $18.58 \pm 0.58$ & $20.63 \pm 0.94$ & $20.92 \pm 1.07$ \\
\hline \multirow{3}{*}{$\begin{array}{c}\text { Hidnfoot length }(\mathrm{cm}) \\
\text { (arm lever for plantaflexors } \\
\text { - version II) }\end{array}$} & I & R-R & $5.24 \pm 0.37$ & $5.16 \pm 0.34$ & $5.85 \pm 0.45$ & $5.79 \pm 0.47$ \\
\hline & II & R-R & $5.11 \pm 0.37$ & $5.10 \pm 0.34$ & $5.89 \pm 0.42$ & $5.84 \pm 0.42$ \\
\hline & III & R-RR & $5.18 \pm 0.34$ & $5.12 \pm 0.35$ & $5.86 \pm 0.44$ & $5.79 \pm 0.45$ \\
\hline \multirow{3}{*}{$\begin{array}{c}\text { Foot length without } \\
\text { hindfoot }(\mathrm{cm}) \text { (arm lever for } \\
\text { dorsiflexors) }\end{array}$} & I & $\mathrm{R}-\mathrm{R}$ & $19.41 \pm 0.82^{*}$ & $19.62 \pm 0.74^{*}$ & $21.39 \pm 1.04$ & $21.58 \pm 0.99$ \\
\hline & II & R-R & $19.52 \pm 0.74^{*}$ & $19.72 \pm 0.74^{*}$ & $21.68 \pm 1.31$ & $21.84 \pm 1.25$ \\
\hline & III & R-RR & $19.37 \pm 0.81^{*}$ & $19.59 \pm 0.75^{*}$ & $21.42 \pm 1.04$ & $21.59 \pm 1.01$ \\
\hline
\end{tabular}

$p=$ statistical significance for the $t$ test for dependent variables $\left({ }^{*} p<0.05 ; * * p<0.01 ; * * p<0.001\right)$. For the description of laterality variants, see Table 1. 
i.e., $53.4 \%$ of women and $50.0 \%$ of men, conducted the tests with the right lower limb, than in variants I and II (ipsilateral asymmetry, homogeneous laterality, variant III, type R-RR, right-handed - right-footed jump - rightfooted ${ }^{\text {kicking a ball }}$ ). As far as the type II R-LR type, i.e., right-handed subjects, whose leading limb during a vertical jump was the left limb, but who kicked a ball with their right limb, the percentage of women was twice as high as the percentage of men $(33.3 \%$ and $15.4 \%$, respectively). In variant III, R-RL type, i.e., right-handed subjects whose leading limb during a jump was the right limb, but who kicked a ball with their left limb, the percentage of women was only half the percentage of men ( $6.7 \%$ and $15.4 \%$, respectively)

Due to the sizes of groups with particular types of laterality, statistical analysis was only conducted for the group of right homogeneity (right-handed; right-footed) in all three variants of limb laterality type assessment. The analysed features and indices for right and left sides for each variant, are presented separately for women and for men in Tables 2 through 5.

Arithmetic means of body mass, height, and BMI for both groups for all analysed variants of homogeneous right laterality (types I R-R, II R-R, III R-RR) are presented in Table 1.

With the self-evident differences between sexes in terms of body height, mass and BMI (all of them highly statistically significant, $\mathrm{p}<0.001$ ), no statistically significant differences were found between arithmetic means of these features in the three variants of limb dominance analysed, i.e., I R-R, II R-R, III R-RR, neither in the group of females nor in the group of males. The arithmetic means for the BMI were within the norm set by the World Health Organisation [26] (BMI for women 19-24, for men 20-25).

Arithmetic means of chosen features and indices for right and left feet for all analysed variants of homogeneous right laterality (types I R-R, II R-R, III R-RR) in women and in men are presented in Tables 2 and 3.

On the basis of analysis of arithmetic means of the studied features, we found statistically significant differences in foot length in right-handed women who in the kick test kicked a ball with the right lower limb (variant II R-R). Their right feet were shorter, $p<0.01$; $W_{\text {asym }}=-0.77 \%$. In women, foot length without hindfoot (arm lever for dorsiflexors) was shorter in the right foot

Table 3. Arithmetic means $( \pm \mathrm{SD})$ of chosen traits of right and left feet for all for all analysed variants of homogeneous right laterality.

\begin{tabular}{|c|c|c|c|c|c|c|}
\hline \multirow[t]{2}{*}{ Traits } & \multirow[t]{2}{*}{$\begin{array}{c}\text { Laterality } \\
\text { variant }\end{array}$} & \multirow[t]{2}{*}{ Type } & \multicolumn{2}{|c|}{$\begin{array}{c}\text { Women } \\
\text { I R-R } \mathrm{n}=18 \\
\text { II R-R } \mathrm{n}=26 \\
\text { III R-RR } \mathrm{n}=16\end{array}$} & \multicolumn{2}{|c|}{$\begin{array}{c}\text { Men } \\
\text { I R-R } \mathrm{n}=17 \\
\text { II R-R } \mathrm{n}=17 \\
\text { III R-RR } \mathrm{n}=13\end{array}$} \\
\hline & & & $\begin{array}{l}\text { Right side } \\
(\bar{x} \pm \mathrm{SD})\end{array}$ & $\begin{array}{l}\text { Left side } \\
(\bar{x} \pm \mathrm{SD})\end{array}$ & $\begin{array}{l}\text { Right side } \\
(\bar{x} \pm \mathrm{SD})\end{array}$ & $\begin{array}{l}\text { Left side } \\
(\bar{x} \pm \mathrm{SD})\end{array}$ \\
\hline \multirow{3}{*}{ Foot width $(\mathrm{cm})$} & $\mathrm{I}$ & R-R & $9.34 \pm 0.41$ & $9.33 \pm 0.49$ & $10.38 \pm 0.40$ & $10.41 \pm 0.54$ \\
\hline & II & $\mathrm{R}-\mathrm{R}$ & $9.31 \pm 0.38$ & $9.28 \pm 0.78$ & $10.48 \pm 0.63$ & $10.55 \pm 0.68$ \\
\hline & III & R-RR & $9.26 \pm 0.35$ & $9.22 \pm 0.49$ & $10.42 \pm 0.44$ & $10.44 \pm 0.55$ \\
\hline \multirow{3}{*}{$\begin{array}{l}\text { Height sphyrion } \\
\text { medale }(\mathrm{cm})\end{array}$} & I & $\mathrm{R}-\mathrm{R}$ & $6.85 \pm 0.41$ & $6.91 \pm 0.50$ & $7.36 \pm 0.64^{*}$ & $7.54 \pm 0.63^{*}$ \\
\hline & II & $\mathrm{R}-\mathrm{R}$ & $6.90 \pm 0.39$ & $6.96 \pm 0.48$ & $7.35 \pm 0.63^{*}$ & $7.55 \pm 0.66^{*}$ \\
\hline & III & R-RR & $6.85 \pm 0.42$ & $6.90 \pm 0.53$ & $7.30 \pm 0.70^{*}$ & $7.50 \pm 0.71^{*}$ \\
\hline \multirow{3}{*}{$\begin{array}{l}\text { Height sphyrion } \\
\text { laterale }(\mathrm{cm})\end{array}$} & I & R-R & $5.01 \pm 0.27$ & $4.95 \pm 0.23$ & $5.38 \pm 0.55$ & $5.36 \pm 0.63$ \\
\hline & II & R-R & $4.98 \pm 0.42$ & $4.91 \pm 0.37$ & $5.57 \pm 0.55$ & $5.52 \pm 0.61$ \\
\hline & III & R-RR & $5.02 \pm 0.28$ & $4.96 \pm 0.25$ & $5.45 \pm 0.57$ & $5.46 \pm 0.68$ \\
\hline \multirow{3}{*}{$\begin{array}{l}\text { Height naviculare } \\
\qquad(\mathrm{cm})\end{array}$} & I & $\mathrm{R}-\mathrm{R}$ & $6.36 \pm 0.44$ & $6.33 \pm 0.42$ & $7.06 \pm 0.51$ & $7.03 \pm 0.52$ \\
\hline & II & $\mathrm{R}-\mathrm{R}$ & $6.46 \pm 0.48$ & $6.42 \pm 0.43$ & $7.15 \pm 0.59$ & $7.16 \pm 0.62$ \\
\hline & III & R-RR & $6.38 \pm 0.47$ & $6.35 \pm 0.44$ & $7.08 \pm 0.58$ & $7.09 \pm 0.58$ \\
\hline \multirow{3}{*}{$\begin{array}{l}\text { Clarke's angle } \\
\text { (degrees) }\end{array}$} & I & $\mathrm{R}-\mathrm{R}$ & $49.29 \pm 3.61^{* * *}$ & $46.63 \pm 4.02^{* * *}$ & $48.88 \pm 10.02$ & $48.32 \pm 9.81$ \\
\hline & II & R-R & $48.29 \pm 4.63^{* * *}$ & $46.23 \pm 5.12^{* * *}$ & $48.34 \pm 10.12$ & $47.93 \pm 9.91$ \\
\hline & III & R-RR & $49.38 \pm 3.91^{* * *}$ & $46.47 \pm 4.11^{* * *}$ & $48.29 \pm 11.31$ & $48.04 \pm 11.02$ \\
\hline
\end{tabular}

$p=$ statistical significance for the $t$ test for dependent variables $\left({ }^{*} p<0.05 ;{ }^{*} p<0.01{ }^{* * *} p<0.001\right)$. For the description of laterality variants, see Table 1. 
for all possible variants of laterality, i.e., in right-handed women whose leading limb during a jump was the right lower limb (variant I R-R: $p<0.05, W_{\text {asvm }}=-1.07 \%$ ); in right-handed women who kicked a ball with the right lower limb (variant II R-R: $p<0.05, W_{\text {asym }}=-1.02 \%$ ), and in right handed women in whom both the leading limb during a jump was the right lower limb and who kicked a ball with the right lower limb (variant III R-R: $\left.p<0,05 ; W_{\text {asym }}=-1,13 \%\right)$. In the group of men, the results of analysis were slightly different. In this group, for all assessed laterality variants, the test for significant differences for dependent variables revealed significant differences, though only on the brink of the significance threshold set, in that the foot length without toes was greater in the left (non-preferred) limb (arm lever for plantaflexors - version I), variant I R-R: $p<0.1$, $W_{\text {asym }}=-1.26 \%$; variant II R-R: $p<0.1, W_{\text {asym }}=-1.05 \%$; variant III R-RR: $p<0.1 W_{\text {asym }}=-1.40 \%$.
A comparison of Table 3 data revealed the following highly statistically significant difference only for the group of women: the Clarke's angle, which describes the longitudinal arches, was lower in left limb for all laterality variants (variant I R-R: $p<0.001, W_{\text {asym }}=5.55 \%$; variant II R-R: $p<0.001, W_{\text {asvm }}=4.36 \%$; variant III R-RR: $\left.p<0.001, W_{\text {asvm }}=6.07 \%\right)$. However, in male right-handed right-footers (in whom the right limb was the dominant limb both when kicking a ball and during a jump), the foot height to the sphyrion mediale point was statistically significantly greater in the left limb (propulsive during a jump and lending support in kicking a ball) in all analysed laterality assessment variants (variant I R-R: $p=0.039, W_{\text {asym }}=-2.42$; variant II R-R: $p<0.05, W_{\text {asym }}=-2.69 \%$; variant III R-RR: $p=0.046$, $\left.W_{\text {asym }}=-2.70 \%\right)$. The foot height to the sphyrion mediale point is considered in the longitudinal foot arch index (see Table 4, $\mathrm{WD}_{1}$ ).

Table 4. Arithmetic means $( \pm S D)$ of chosen indices of right and left feet for all for all analysed variants of homogeneous right laterality.

\begin{tabular}{|c|c|c|c|c|c|c|}
\hline \multirow[t]{2}{*}{ Indices } & \multirow[t]{2}{*}{$\begin{array}{l}\text { Laterality } \\
\text { variant }\end{array}$} & \multirow[t]{2}{*}{ Type } & \multicolumn{2}{|c|}{$\begin{array}{c}\text { Women } \\
\text { I R-R } \mathrm{n}=18 \\
\text { II R-R n }=26 \\
\text { III R-RR n }=16\end{array}$} & \multicolumn{2}{|c|}{$\begin{array}{c}\text { Men } \\
\text { I R-R } \mathrm{n}=17 \\
\text { II R-R } \mathrm{n}=17 \\
\text { III R-RR } \mathrm{n}=13\end{array}$} \\
\hline & & & $\begin{array}{l}\text { Right side } \\
(\bar{x} \pm \mathrm{SD})\end{array}$ & $\begin{array}{l}\text { Left side } \\
(\bar{x} \pm \mathrm{SD})\end{array}$ & $\begin{array}{l}\text { Right side } \\
(\bar{x} \pm \mathrm{SD})\end{array}$ & $\begin{array}{l}\text { Left side } \\
(\bar{x} \pm \mathrm{SD})\end{array}$ \\
\hline \multirow{3}{*}{$\begin{array}{l}\mathrm{WD}_{1} \text { Index longitudinal arch } \\
\text { index I }\end{array}$} & I & R-R & $27.80 \pm 1.6$ & $27.90 \pm 1.9$ & $27.09 \pm 2.7$ & $27.58 \pm 2.5$ \\
\hline & II & $\mathrm{R}-\mathrm{R}$ & $28.03 \pm 1.4$ & $28.04 \pm 1.8$ & $26.70 \pm 2.5^{*}$ & $27.34 \pm 2.6^{*}$ \\
\hline & III & R-RR & $27.90 \pm 1.5$ & $27.92 \pm 1.9$ & $26.79 \pm 2.7$ & $27.41 \pm 2.6$ \\
\hline \multirow{3}{*}{$\begin{array}{l}\mathrm{WD}_{2} \text { Index longitudinal arch } \\
\text { index II }\end{array}$} & I & R-R & $25.81 \pm 1.7$ & $25.54 \pm 1.5$ & $25.97 \pm 2.1$ & $25.85 \pm 2.3$ \\
\hline & II & R-R & $26.21 \pm 1.7^{*}$ & $25.85 \pm 1.5^{*}$ & $25.99 \pm 2.6$ & $25.92 \pm 2.3$ \\
\hline & III & R-RR & $26.00 \pm 1.6$ & $25.70 \pm 1.5$ & $26.00 \pm 2.2$ & $25.88 \pm 2.4$ \\
\hline \multirow{3}{*}{$\begin{array}{l}\mathrm{WD}_{3} \text { Index longitudinal arch } \\
\text { index III }\end{array}$} & I & R-R & $36.60 \pm 2.3$ & $37.12 \pm 2.9$ & $36.82 \pm 3.3$ & $36.22 \pm 3.3$ \\
\hline & II & $\mathrm{R}-\mathrm{R}$ & $37.00 \pm 2.0$ & $37.24 \pm 2.7$ & $35.31 \pm 3.1$ & $35.92 \pm 3.3$ \\
\hline & III & R-RR & $36.72 \pm 2.2$ & $37.16 \pm 3.0$ & $35.41 \pm 3.3$ & $35.89 \pm 3.3$ \\
\hline \multirow{3}{*}{$\begin{array}{l}\mathrm{WD}_{4} \text { Index longitudinal arch } \\
\text { index IV }\end{array}$} & I & $\mathrm{R}-\mathrm{R}$ & $33.98 \pm 2.3$ & $33.90 \pm 2.2$ & $34.36 \pm 2.6$ & $33.96 \pm 3.2$ \\
\hline & II & R-R & $34.60 \pm 2.4$ & $34.32 \pm 2.3$ & $34.38 \pm 2.6$ & $34.01 \pm 3.1$ \\
\hline & III & R-RR & $34.20 \pm 2.3$ & $34.18 \pm 2.3$ & $34.35 \pm 2.8$ & $33.91 \pm 3.2$ \\
\hline \multirow{3}{*}{ WS Index transverse arch index } & $\mathrm{I}$ & $\mathrm{R}-\mathrm{R}$ & $2.64 \pm 0.1$ & $2.69 \pm 0.4$ & $2.61 \pm 0.1$ & $2.63 \pm 0.2$ \\
\hline & II & $\mathrm{R}-\mathrm{R}$ & $2.65 \pm 0.1$ & $2.69 \pm 0.3$ & $2.64 \pm 0.2$ & $2.63 \pm 0.2$ \\
\hline & III & R-RR & $2.65 \pm 0.1$ & $2.71 \pm 0.4$ & $2.62 \pm 0.1$ & $2.63 \pm 0.2$ \\
\hline \multirow{3}{*}{$\mathrm{WT}_{1}$ Index hindfoot index I } & I & $\mathrm{R}-\mathrm{R}$ & $21.26 \pm 1.4^{*}$ & $20.81 \pm 1.3^{*}$ & $21.46 \pm 1.3$ & $21.14 \pm 1.2$ \\
\hline & II & $\mathrm{R}-\mathrm{R}$ & $20.76 \pm 1.5$ & $20.54 \pm 1.3$ & $21.40 \pm 1.5$ & $21.12 \pm 1.3$ \\
\hline & III & R-RR & $21.12 \pm 1.5$ & $20.72 \pm 1.3$ & $21.48 \pm 1.3$ & $21.15 \pm 1.2$ \\
\hline \multirow{3}{*}{$\mathrm{WT}_{2}$ Index hindfoot index II } & I & $\mathrm{R}-\mathrm{R}$ & $27.98 \pm 1.9$ & $27.66 \pm 1.7$ & $28.40 \pm 1.5^{*}$ & $27.76 \pm 1.5^{*}$ \\
\hline & II & R-R & $27.40 \pm 1.9$ & $27.27 \pm 1.7$ & $28.33 \pm 2.1^{*}$ & $27.75 \pm 1.7^{*}$ \\
\hline & III & R-RR & $27.78 \pm 1.9$ & $27.55 \pm 1.8$ & $28.42 \pm 1.9^{*}$ & $27.70 \pm 1.6^{*}$ \\
\hline
\end{tabular}

$p=$ statistical significance for the $\mathrm{t}$ test for dependent variables $\left({ }^{*} \mathrm{p} \leq 0.05\right)$. For the description of laterality variants, see Table 1. 


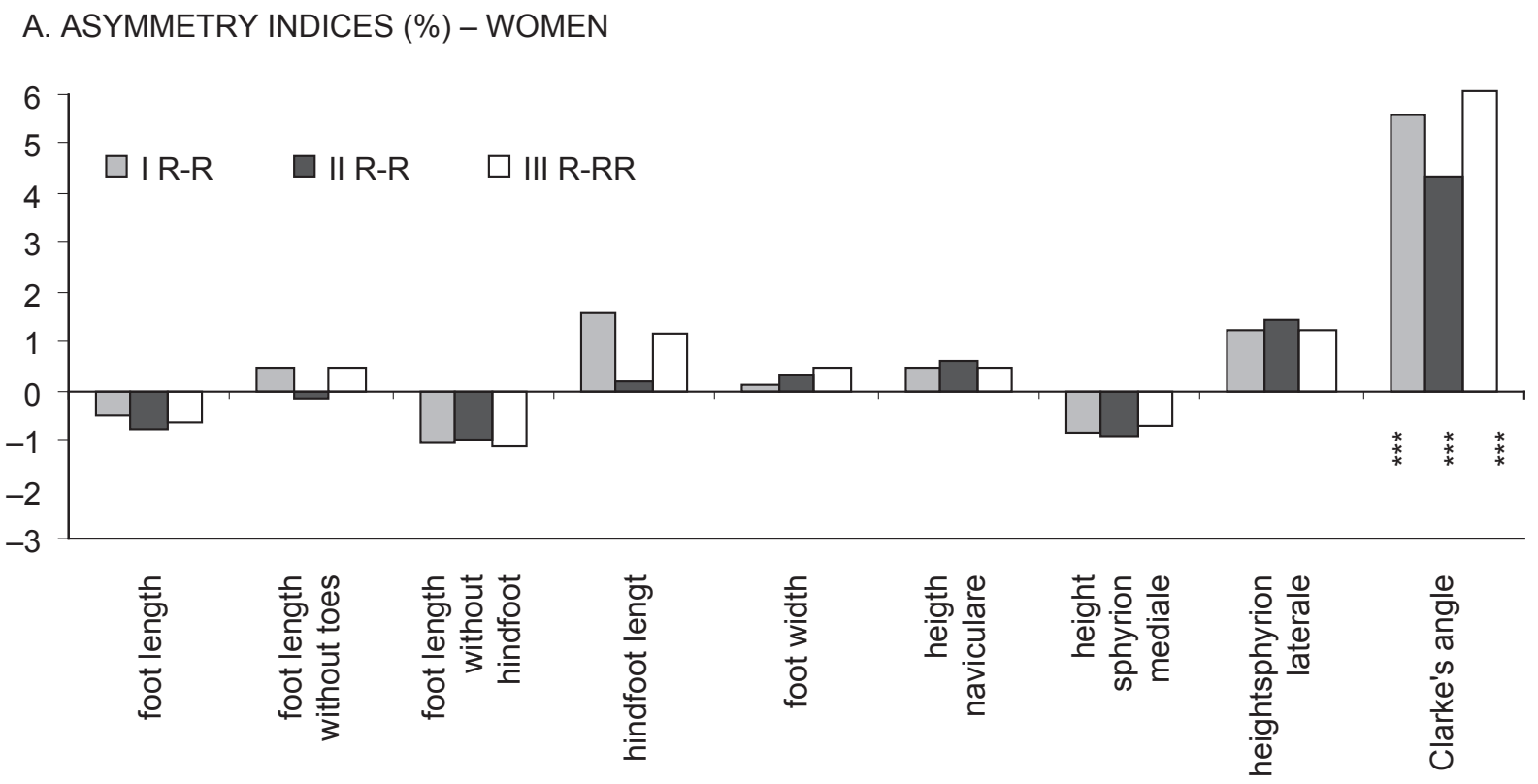

B. ASYMMETRY INDICES (\%) - MEN

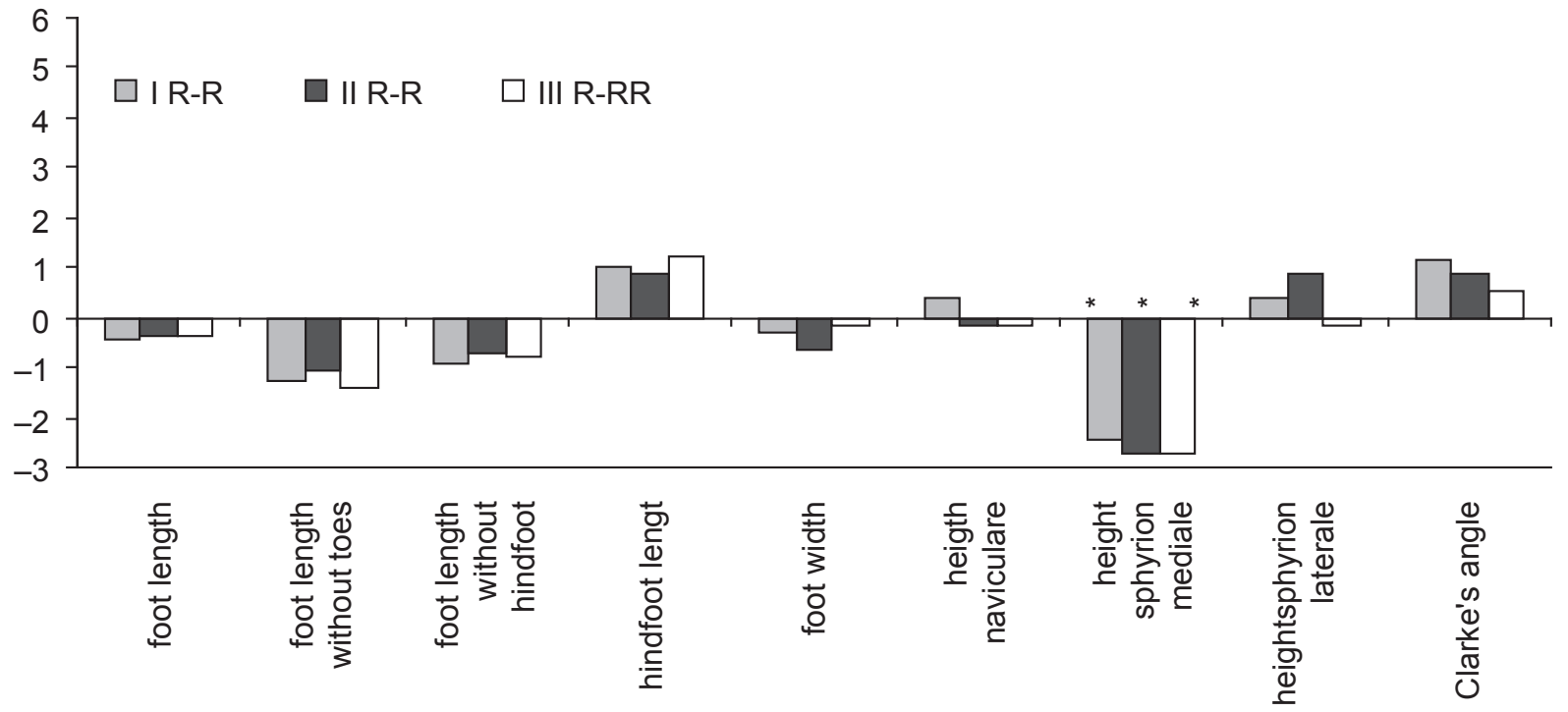

Figure 5. Asymmetry indices of chosen traits of right and left feet of women (Figure A) and men (Figure B) for all analysed variants of homogeneous right laterality (test for dependent trials $* p<0.05 ; * * p<0.001$ ). For the description of laterality variants and group sizes, see Table 1 . Negative values of asymmetry indices point at a given value being greater for the left limb.

Figure 5 presents graphic representations of asymmetry indices for chosen features of female and male feet for all analysed variants of homogeneous right laterality (types I R-R, II R-R, III R-RR).

Analysis of longitudinal arch index $\mathrm{WD}_{1}$ (Table 4), which expresses the foot height to the sphyrion mediale point as a percentage of foot length, confirmed the greater index values for the left side for the laterality variant II only, i.e., in the group of right-handed men who kicked a ball with their right lower limb. In the group of men, the values of the $\mathrm{WT}_{2}$ index (which expresses hindfoot length as a percentage of foot length without toes) were statistically significantly higher for the right side (variant I R-R: $p<0.05$; variant II R-R: $p=0.063$; variant III R-RR: $p<0.05$ ). Analysis of the remaining indices of right and left lower limbs, both in the group of women and in the group of men, did not reveal any statistically significant differences between the considered variants of limb laterality.

With the self-evident, statistically significant dimorphic differences in absolute values of anthropometric features of female and male feet (for most of the 
differences, a statistical significance of $p \leq 0.001$ ), we found no such differences when comparing percentage foot indices, nor did we find such differences when comparing the Clarke's angle values for longitudinal arches. The only exception (and only in the limb laterality variant II R-R) were two longitudinal arch indices for right foot, which express the foot height up to the sphyrion mediale point as percentage of foot length with toes $\left(\mathrm{WD}_{1}\right)$ and without toes $\left(\mathrm{WD}_{3}\right)$. These indices revealed that female right-handed right-footers (in the test for kicking a ball- laterality assessment variant II R-R) had better longitudinal foot arches in right feet than men $\left(\mathrm{WD}_{1}\right.$ : women $\bar{x}=28.03$; $\operatorname{men} \bar{x}=26.70$; $p<0.05$ and $\mathrm{WD}_{3}$ : women $\bar{x}=37.00$; men $\bar{x}=35.31$; $p<0.05)$. Other longitudinal arch indices, however, did not confirm this.

Dimorphic indices of chosen foot features in women and in men for all analysed variants of homogeneous right laterality (types I R-R, II R-R, III R-RR) are presented in Figure 6.

Features considered dimorphic are those in which the difference of arithmetic means is greater than 1 from standard deviation (SD) for the males group. These features, for both right and left feet, were all features related to foot length, width, and height up to the naviculare point. Features such as foot heights up to the sphyrion mediale and sphyrion laterale points, and Clarke's angle values, did not reveal significant differences.

\section{Discussion}

When considering the division into right and left limbs (in the sagittal plane), the right limbs (both upper and lower) are usually associated with manipulating, precise, dexterous, leading and initiating functions; whereas the left limbs are associated with supporting, propulsive and force-related functions. In their study of functional gait asymmetry, Sadeghi et al. [22] proved that role of one of the limbs is to provide propulsion, and the role of the other is to cushion shock (amortize). While available information on upper limb laterality is usually consistent and does not cause doubts, the data from different authors on lower limb laterality are quite divergent, and at times even contradictory. Doubts may concern the methods used for assessing footedness as well as the interpretation of the results. In her thorough study on human functional limb laterality and its influence on the motor coordination, OlexZarychta [16] found that conclusions made in studies on functional laterality of human limbs are usually rather cautious, and that authors of these conclusions

A. DIMORPHISM INDICES - right side

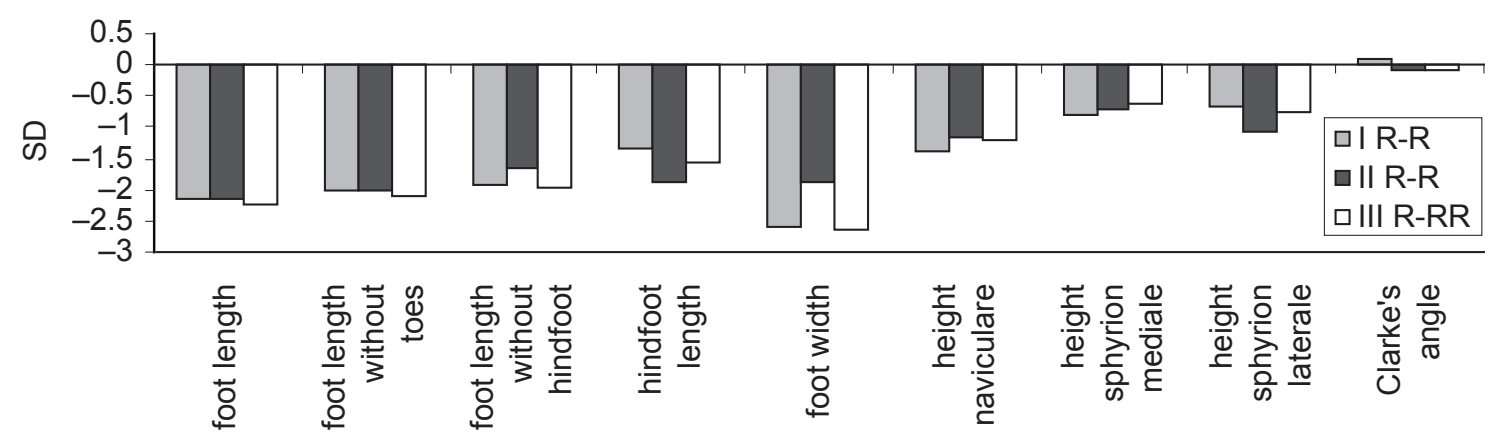

B. DIMORPHISM INDICES - left side

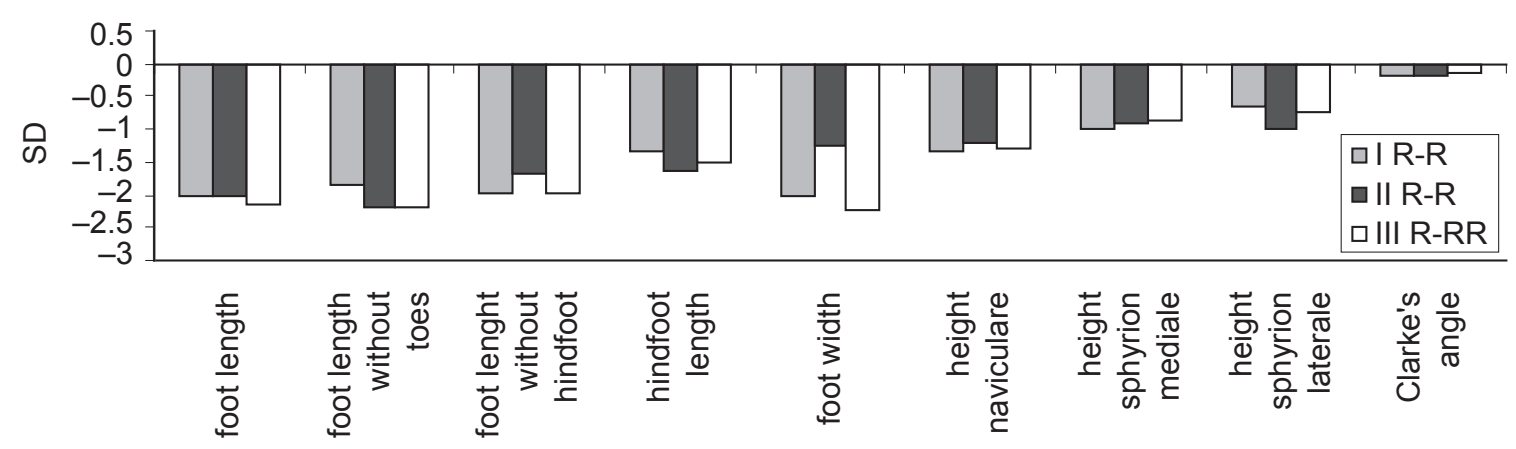

Figure 6. Dimorphism indices of chosen foot traits for the right side (Figure A) and for the left side (Figure B) for all analysed variants of homogeneous right laterality. For the description of laterality variants and group sizes, see Table 1. Negative values of dimorphism indices point at a given value being greater in men. 
rarely generalize them on populations as a whole. OlexZarychta thought that the reasons for this caution were the lack of basic diagnostic tools and methodological difficulties in conducting studies. Information on functional limb laterality is usually gathered in interviews and is often supplemented by various tasks demanding the activity of one or the other limb. The questionnaires that examine footedness contain diverse sets of activities, which test diverse elements of lower limb activity, diverse forms of its manifestation, and diverse functional character. Some tests have only covered manipulating or leading functions [9, 18, 25]; others have additionally considered supporting or propulsive functions, which has led to constructing mixed sets of tasks, combining both task types mentioned above $[4,6,7]$. However, the results of both task types have been analysed together (e.g., points for different tasks were summed, with no differentiation shown for task type) [6], which might have led to eliminating or masking the real differences related to limb laterality.

Various authors used foot measurements, such as foot length and width, as additional data in determining the preferred limb [11]. These methods, however, have not provided satisfactory answers, were not reliable enough, and such results were inconsistent. The footedness pattern determined on such bases was ambiguous. Singh et al. [23] reported that some of the studies revealed greater mass and length on the right side (studies by Latimer and Lowrance in 1965), whereas others revealed greater mass and length on the left side (studies by Trotter and Gleser in 1952). Singh et al. [23], who conducted measurements of mass and length on 50 pairs of lower limbs skeletons of right-handed subjects, found that mass and length asymmetries in bones taken from proximal and distal parts of lower limbs are unequal. Most right shinbones were longer than right shinbones, both in females and in males, whereas most femurs were longer for the left side, again for both sexes $(p<0.01)$. At the same time, the authors found that in most of the examined skeletons the right femurs, fibulas, and tibias were heavier than those on the left ( $p<0.001)$. As for the mass of remaining bones, no statistically significant differences were found between the right and left sides. Mass asymmetry was less pronounced in tarsus and metatarsus bones in men, while in women these bones were usually heavier on the right side. The bone mass for the whole limb was greater on the right side in both female and male skeletons. Singh et al. found that the right and left side bone mass differences decreased in the distal direction.

The assessment criteria for result interpretation varied, as well. For instance, when considering the natural, contralateral role of limbs cooperating with each other, the most common types will be right- handedness and left-footedness (with the upper right limb doing the precise movements and lower left limb lending support). When describing functional asymmetry, numerous authors actually consider in their assessment criteria the manipulating (precision) functions, which are characteristic for the upper limb, and stabilizing (force, propulsive) functions for the lower limb. This usually results in a contralateral functional system. This is the system to which Sadeghi et al. [21] referred when they quoted Von Bornin's statement from 1962: that we, humans, are usually right-handed and left-footed. Wolański [28] expressed a similar opinion when he stated that contralateral asymmetry (right hand - left foot) is related to the humans' upright body position and therefore constitutes a species' feature of Homo sapiens. He also claimed that right-handedness conditions a more frequent use of the lower left limb to maintain balance or to generate force more efficiently. In light of such limb laterality interpretation, however, one would have to accept the bilateral hemisphere dominance, i.e., left hemisphere dominance for the upper right limb (right-handedness), and right hemisphere dominance for the lower left limb (left-footedness), when considering intersection of most nerve tracts transmitting impulses to and from the central nervous system. However, if in interpreting the results for both limbs we consider identical kinds of motor activity (homogeneous specificity of movement, similar character of movement, similar kind of load, e.g., manipulating, precision, and dexterity), then the most common type will be the right-handed - right-footers. Then, because of the location of nerve centres for the right side, only the left hemisphere will be the dominant one. These criteria in assessing footedness were applied by Chapman et al. [3], Gabbard et al. [8] and Peters [18], in that they assumed that the limb initiating or leading the movement, also referred to as the mobilizing limb for its main role in precision movement, is the preferred foot; whereas the support limb, or the propulsive limb, is the non-preferred foot. Had the authors we had mentioned earlier, in assessing side dominance, used the interpretation of Chapman et al. [3], Gabbard et al. [8] and Peters [18], who would treat the leading limb, counter-movement limb (and not the propulsive limb) as the initiating limb during a jump, they would have ended up not with contralateral (i.e., crossed) asymmetry, but the ipsilateral (homogeneous) asymmetry instead.

Numerous authors confirm that homogeneous right laterality is the most common type of limb preference $[4,7,19]$. Dębicka [5] expresses a similar opinion; she also states that the percentage of subjects with crossdominance of hand and leg is limited. In her studies of functional asymmetries in upper and lower limbs 
in 7-year-old girls and boys, she proved that the lower right limb is more often the preferred limb both in results for single trials and in mixed trials (she determined the functional domination of lower limbs in two tests, i.e., hopscotch and kicking a block). Olex-Zarychta [16] stated that some authors [7] differentiated between two separate kinds of footedness, functional and strength, which manifest in various motoric activities. The strength footedness manifests in the choice of the propulsive leg in high jump or in hurdle race. It is not related, however, to the limb preferred in the skilled activities. The tests have proved that the functionally dominant limb muscles are often weaker than the strength dominant leg muscles, which may point to a higher motoric specialization of lower limbs than is commonly recognized [16]. Similarly, Demura et al. [4] tested footedness in two ways, i.e., separately in tasks demanding force (here the dominant leg was the leg lending postural support at kicking a ball, the propulsive leg during a jump, and the propulsive leg in hopping on one leg), and separately in manipulating activities (here, the dominant limb was the limb kicking a ball, the limb picking the object from the floor, and the limb drawing circles on the floor).

The functional preference assessment of lower limb "The Waterloo Footedness Questionnaire" [6] contains 10 questions on two kinds of activities (five questions for manipulating functions, i.e., kicking a ball at a target, smoothing sand at the beach, picking up a marble with one's toes, stomping on a bug, and pushing a shovel into the ground; five questions for stabilizing and balancing functions in activities such as: standing on one foot, stepping up onto a chair, balancing on one foot on a railway track, hopping on one leg, and putting weigh on one foot while relaxed standing). In their study concerning the connection between lower limb laterality with lower limb asymmetry in flexibility, stability, power, strength and muscle endurance, Valdez et al. [25] used a questionnaire that contained three questions: Which leg do you use to kick a ball?; Which leg do you use to stomp on an objects?; and Which leg do you use to smooth sand on the beach? Hebbal et al. [9] assessed footedness on answers to questions on nine activities, from which three activities they eventually considered "ideal" to assess footedness, i.e., kicking a ball, moving an object with foot, and stamping feet. We decided to choose two tasks form the Waterloo Questionnaire to assess footedness: kicking a ball at a target (the dominant limb being the limb kicking a ball) and vertical jump (the dominant limb being the leading limb, countermovement limb), in which we applied the interpretation of limb dominance by Chapman et al. [3], Gabbard et al. [8], and Peters [18].
In our study, the subjects were qualified into several groups, depending on their limb laterality (three variants of tests for limb preference). In all the analysed laterality variants, subjects with homogeneous right dominance of upper and lower limb prevailed. In the first variant these were right-handed right-footers I R-R type; they used the right foot for leading during a vertical jump, and it was the dominant foot. In the second variant these were right-handed right-footers II R-R type; they kicked a ball with the right foot, and it was the dominant foot. In the third variant these were right-handed right-footers III R-RR type, the right foot being the dominant one in both tests. The connection between the dominance of the right hand with the dominance of the right foot has been established by, among others, Peters et al. [19], who found that $95 \%$ of their right-handed subjects preferred to kick a ball with right foot. Our results support this tendency, as this preference was found in $86.7 \%$ of women and $65.4 \%$ of men. Elias et al. [6] state that most adult right-handers prefer the right foot in doing skilled activities, such as kicking a ball, smoothing out sand, picking up objects with their toes, pushing a shovel into the ground, balancing on one foot, balancing on a railway track, etc.; only $1.5 \%$ to $6 \%$ of right-handers prefer to do these activities with their left foot. Beling et al. [1], in their study on women aged 21-25 years, analysed the lower limb preference in two positions, sitting and standing, during activities requiring leading moves (wide and extensive) and during skilled activities (subtle and delicate). The tasks in both positions were the same, i.e., kicking a ball, lifting one's leg over a box, picking up a marble with one's toes, and drawing a triangle with one's hallux. The sitting position allowed for eliminating the supporting function of the lower limb. It turned out that regardless of the position in which the tasks were performed, the right-handers used the right foot in $90 \%$ of cases to do the skilled activities (e.g., picking up a marble with one's toes). Similarly, in broader moves, requiring a lead (e.g., kicking a ball), $100 \%$ the right-handed women preferred the right foot. By comparison, the authors noted that only $60 \%$ of the lefthanded women used the left foot for this task. These authors therefore concluded that individual limb preferences depend on the type of the task performed (whether it is static or dynamic; whether it requires a extensive movement or a precise and small movement). A significant relationship between the lateral preferences of hand and foot was confirmed by Kauranen et al. [10]. Similarly, in her studies on functional asymmetry of lower and upper limbs in 7-year-old girls and boys, using two trials to assess domination, i.e., kicking a block and hopscotch, Dębicka [5] found that most subjects present homogeneous right dominance 
(in right-handers, e.g., in kicking a block test: girls $91.3 \%$, boys $91.7 \%$; in the hopscotch test: girls $71.0 \%$, boys $67.6 \%$; and in the combined results of both tests: girls $57.2 \%$, boys $50.3 \%$ ). According to Wolański [28], the more frequent use of the lower right limb for the skilled activities is presumably a manifestation of the so-called transfer of established habit (transfer of motor function) from the upper limb to the lower limb within nerve centres. According to Carey et al. [2], the non-preferred foot is just as experienced in walking, running, standing and balancing the body as the preferred foot, and yet behaviours such as kicking a ball are consistently performed with the right limb (according to this author, approximately $80 \%$ ). The data discussed above apply to the right-handed right-footers. The percentage of subjects with cross-dominance of hand and foot is considerably lower.

A distinct issue was assessing connections between functional and morphological asymmetries. The side diversification of anthropometric features, i.e., length, width, size of various body parts, and especially of upper limbs, has been discussed by numerous authors. There are, however, relatively fewer reports on the impact of laterality on morphological diversification of lower limbs, particularly on the distal parts: the feet. Sadeghi et al. [21] quoted Ingelmark to state that he had found a longer lower left limb in $85 \%$ of right-handers aged 14-20 years. These results are consistent with Peters' observations [18]: he noted that in adult right-handers, the lower left limb shows a tendency to be longer and heavier, which is consistent with its role of lending postural support. According to Wolański [28], the lower left limb was longer in $72 \%$ of subjects, and that $54 \%$ of subjects had larger circumferences in the left shank. In his opinion, this also impacts the changes to the microstructure and composition of tissues: for instance, the "jumping" leg has a layer of cortical bone up to $5 \mathrm{~mm}$ thicker. As for the foot, the most distal part of the lower limb, the results presented by different authors are ambiguous. Mascie-Taylor et al. [12] concluded their study with a statement that male right-handers had larger left feet; contrary to female right-handers, who had larger right feet. Means and Walters [13] discussed correlations between morphological asymmetry of the hand and the handedness, though they did not confirm any similar correlations in feet. In our study, the mean of the left foot was typically longer, though the difference was statistically significant only for the female right-handed right-footers in the variant II R-R. In the variant II RR, in which the dominance of lower limb was assessed on the basis of the kicking a ball test only, in the group of female right-handed right-footers, the right foot (the dominant foot) was shorter, whereas the left foot (non-dominant), which had the stabilizing function, was longer. In this group of subjects, foot length without hindfoot (arm lever for dorsiflexors, i.e., foot extensor muscles) was different it was greater in the left (non-dominant) foot. This was similar in the variant I R-R, in which dominance was assessed on the basis of vertical jump only; i.e., in the group of female right-handers who used the right limb (the dominant limb) to lead during a jump. Again, this was consistent in the variant II R-RR, for subjects who were right-footed in both trials. We need to stress that in all analysed variants, the left foot (non-dominant) was the propulsive foot during the vertical jump, and the supporting foot while kicking a ball.

In all the laterality variants we analysed in this study, for both the men's and women's groups, the Clarke's angle, which characterizes the longitudinal foot arch, was greater for right feet (the dominant feet); however, this difference was statistically significant, and confirmed with asymmetry indices, in the women's group only. Left feet, which in asymmetrical tasks serve the supporting, stabilizing or propulsive functions, more often bear the weight of the whole body and display smaller Clarke's angles. The above results for Clarke's angle are not consistent with the index of longitudinal arches, which denotes the foot height up to the sphyrion mediale point as a percentage of foot length. Both in women and in men this parameter pointed to a slightly better longitudinal arch in left feet (the non-dominant foot, i.e., supporting while kicking a ball and propulsive during a vertical jump); however, the differences were not statistically significant. Neither are these differences were confirmed by other characteristics and indices of longitudinal foot arches, such as foot height up to sphyrion laterale point and up to naviculare point, or the longitudinal arch indices $\mathrm{WD}_{1}-\mathrm{WD}_{4}$, with the exception for the $\mathrm{WD}_{2}$ index, which was significantly greater in the right foot, and which denoted the foot height up to the naviculare point as a percentage of foot length, in female right-handers who kicked a ball with their right feet (variant II R-R). In men it was slightly different, i.e., in none of the analysed laterality variants were any differences found between the mean values of Clarke's angle for the right and left foot. However, such differences were found in the height up to the sphyrion point (left feet were higher) and the longitudinal arch index as well, which describes the foot height up to the sphyrion point as a percentage of foot length, was higher for left feet, but only in men who kicked a ball with their right feet (laterality variant II R-R). What follows from the above is that the longitudinal arch indices (Clarke's angle and percentage indices $\left.\mathrm{WD}_{1}-\mathrm{WD}_{4}\right)$ were inconsistent. The inconsistencies may arise from the fact that both kinds of foot arch indices (angle and percentage) describe slightly different 
features of foot arches. The Clarke's angle, measured on the foot print, registers the adherence of the soft foot parts to the ground and depends to a large extent on the muscle structure of the planum; the percentage indices, obtained from direct foot measurements, are in direct proportion to the foot height and in inverse proportion to the foot height.

In the group of male right-handed right-footers (for all the laterality variants), the hindfoot index $\mathrm{WT}_{2}$ for the right and left feet, which describes the hindfoot length as a percentage of foot length without toes, revealed statistically significant differences. This index revealed that the relative hindfoot length (bone arm lever for plantaflexors, with the lever axis located in the ankle joint) was greater in the right foot (the preferred foot, i.e., the foot leading in vertical jump, and the foot kicking a ball). In the left foot (the non-preferred foot, i.e., the foot lending support in asymmetrical tasks, and the propulsive foot during vertical jump), the relative hindfoot length in relation to foot length without toes is shorter (a shorter bone arm lever for plantaflexors). A comparison of the remaining indices for right and left lower limbs, both for the male and female groups, did not reveal any statistically significant differences between the analysed limb laterality variants (footedness).

Owing to Mollison's index, which was used in our study, all differences between feature values for men and women were expressed in "units" of standard deviation for the male group. With the self-evident and statistically significant differences between sexes in terms of absolute values for length, width, and height of male and female feet, in all analysed limb laterality assessment variants (dimorphism index from approximately -1 to approximately $-3 \mathrm{SD}$ ), we found significant differences when comparing both percentage foot indices and Clarke's angle values for longitudinal arches. The exceptions were (and only for the limb laterality variant II R-R, i.e., right-handers in whom the right lower limb was the dominant one when kicking a ball) both longitudinal arch indices for the right foot, which describe the foot height up to the sphyrion mediale point as percentage of foot length with toes $\left(\mathrm{WD}_{1}\right)$ and in its percentage without toes $\left(\mathrm{WD}_{3}\right)$. In light of these indices, female right-handed right-footers had better longitudinal arches in right feet than men. However, other longitudinal arch indices do not confirm this. Mean male feet were longer by approximately $3 \mathrm{~cm}$, wider by approximately $1 \mathrm{~cm}$, and higher by approximately $0.7 \mathrm{~cm}$ than female feet, whereas the Clarke's angle values of longitudinal arches were similar in both sexes - between $46^{\circ}$ and $49^{\circ}$. Numerous authors have examined the existence of dimorphic differences in the type of limb preference and its potential effects. The studies conducted on this matter have not provided an unambiguous answer. Mascie-Taylor et al. [12] suggested that there were strong corrections between the dimorphic diversity and functional asymmetries in limbs, whereas Means et al. [13] did not confirm such correlations. In a similar study on 7-year-old girls and boys, Dębicka [5] did not find differences in the distribution of certain types of limb preference between sexes. Our study provides similar results in adults. We compared arithmetic means of the groups (without considering the lower limb preference) and found highly significant differences between sexes in most of the absolute measurements of the feet; however, we did not find differences in either longitudinal or transverse arches. When we divided the subjects according to their limb preference (into three laterality assessment variants), in the variant II R-R, i.e., right-handers who always kicked a ball with their right feet, we found significant statistical differences between sexes, with higher values in women in two longitudinal arch indices. Female righthanded right-footers had morphological asymmetry in the following features: foot length, foot length without hindfoot (arm lever for dorsiflexors) - these measurement values were higher for the left foot - and the Clarke's angle, which was greater in the right foot. In male right-handed right-footers, we found asymmetry in the foot length without toes (left feet were longer) and in the foot height up to the sphyrion mediale point (left feet were higher). Both indices for longitudinal arches that relate foot height to foot length and foot length without toes, respectively, were statistically significantly higher in women for the right side only.

To conclude:

- in females, the foot that in asymmetrical, onelegged tasks lends support or provides propulsion (the non-dominant limb) had longer forefoot and midfoot (they form the arm lever for dorsiflexors). It had, however, lower foot arches than the foot that leads, initiates the move, or kicks a ball (the dominant limb).

- in males, the foot that in asymmetrical, one-legged tasks lends support or provides propulsion (the nondominant limb) had longer and higher hindfoot and midfoot (they form the arm lever for plantaflexors). It had, however, lower foot arches than the foot that leads, initiates the move, or kicks a ball (the dominant limb).

\section{Conclusions}

In our study, we searched for connections between functional asymmetry of limbs and morphological asymmetry of feet. The analysis of our results does not allow for a claim that laterality of lower extremities had a considerable impact on indices of longitudinal and transverse foot arches. However, some of the morphological (anthropometric) traits of right and left feet demonstrate statistically significant diversity (these traits are greater in the non-dominant limb). In women, 
these were foot length without hindfoot; in men, foot height up to the medial malleous and foot length without toes. We found no other connections between sex and foot structure of lower limb laterality.

With the self-evident and statistically significant differences in terms of foot absolute metrical traits (length, width, and height) in men and women (dimorphism), we did not find such differences between relative values of percentage indices of foot or the Clarke's angle. It seems that the reasons for the differences between men and women in the asymmetries of some of the longitudinal arch parameters might be found in different degree of engagement in various forms of physical activity, in dimorphic diversity of dynamic asymmetry, and in the different ways of loading feet related to differences of height of heels in shoes, and, as a result, in different reactions of passive stabilizers (ligaments) and passive stabilizers (muscles) to these loads.

On the basis of our analysis we have formulated - for the group of homogeneously lateralized righthanded right-footers - the following conclusions:

- in females, the dominant limb's foot is characterized by a shorter bone arm lever for dorsiflexors;

- in males, the dominant limb's foot is characterized by a shorter bone arm lever for plantaflexors.

The development and completion of analyses on the same material currently being prepared for publication concerning the assessment of connections between limb laterality and strength of dorsiflexors and plantaflexors presented in this study may shed some light on the connections between dynamic and morphological foot asymmetries.

\section{References}

1. Beling J., G.A. Wolfe, K.A. Allen, J.M. Boyle (1998) Lower Extremity Preference During Gross and Fine Motor Skills Performed in Sitting and Standing Postures. J. Orthop. Sport Phys., 28: 400-404.

2. Carey D.P., D.T. Smith, D. Martin, G. Smith, J. Skriver, A. Rutland, J. W.Shepherd (2009) The bi-pedal ape: Plasticity and asymmetry in footedness. Cortex., 45: 650-661.

3. Chapman J.P., L.J. Chapman, J.J. Allen (1987) The measurement of foot preference. Neuropsychologia, 25(3): 579-584.

4. Demura S., S. Yamaji, F. Goshi, Y. Nagasawa (2001) Lateral dominance of legs in maximal muscle power, muscular endurance, and grating ability. Percept. Motor Skill., 93: 11-23.

5. Dębicka J. (2004) Functional domination of hands and legs of seven-year-old girls and boys. Ann. UMCS Sect. D. LIX suppl. XIV: 406-410.
6. Elias L.J., M.P. Bryden, M.B. Bulman-Fleming (1998) Footedness is a better predictor than is handedness of emotional lateralization. Neuropsychologia, 36(1): 37-43.

7. Fumoto N. (1989) A study of laterality phenomene by a questionnaire survey mainly as to the definition of footedness. Jap. J. Phys. Educ., 33: 110-118.

8. Gabbard C., M. Iteya (1996) Foot laterality in children, adolescents and adults. Laterality, 1(3): 177-183.

9. Hebbal G.V., V.R. Mysorekar (2006) Evaluation of some tasks used for specifying handedness and footedness. Percept Motor Skill., 102: 163-164.

10. Kauranen K., H. Vanharanta (2001) Relationship between extremities in motor performance. Percept Motor Skill., 92 (1):11-18.

11. Manna I., D. Pradhan, S. Ghosh, S.K. Kar, P. Dhara (2001) A comparative study of foot dimension between adult male and female and evaluation of foot hazards due to using footwear. J. Physiol. Anthrop. Appl. Hum. Sci., 20: 241-246.

12. Mascie-Taylor C.G., A.M. MacLarnon, P.M. Laningan, I.C. McManus (1981) Foot-length asymmetry, sex, and handedness. Science, 212: 1416-1417.

13. Means L.W., R.E. Walters (1982) Sex, handedness and asymmetry of hand and foot length. Neuropsychologia, 20(6): 715-719.

14. Migasiewicz J. (2006) Wybrane przejawy sprawności motorycznej dziewcząt i chłopców w wieku 7-18 lat na tle ich rozwoju morfologicznego. AWF Wrocław Monografie.

15. Nunome H., Y. Ikegami, R. Kozakai, T. Apriantono, S.Sano (2006) Segmental dynamics of soccer instep kicking with the preferred and non-preferred leg. J. Sport Sci., 24(5): 529-541.

16. Olex-Zarychta D. (2010) Lateralizacja funkcjonalna kończyn człowieka i jej uwarunkowania w zakresie koordynacji motorycznej. Monografie AWF Katowice.

17. Osiński W. (2003) Antropomotoryka. Wyd. II. Podręczniki nr 49, AWF w Poznaniu.

18. Peters M. (1988) Footedness: Asymmetries in foot preference and skill and neuropsychological assessment of foot movement. Psychol. Bulletin, 103: 179-192.

19. Peters M., B.M. Durding (1979) Footedness of left - and right hander's. Am. J. Psychol., 92: 133-144.

20. Rahnama N., A.Lees, E.Bambaecichi (2005) Comparison of muscle strength and flexibility between the preferred and non-preferred leg in English soccer players. Ergonomics, 48: 1568-1575.

21. Sadeghi H., P. Allard, F. Prince, H. Labelle (2000) Symmetry and limb dominance in able bodied gait: a review. Gait Posture, 12(1): 34-45.

22. Sadeghi H., P. Allard, M. Duhaime (1997) Functional gait asymmetry in able-bodied subjects. Hum. Movement Sci., 16(2-3): 243-258. 
23. Singh G., C. Mohanty (2005) Asymmetry in the weight and linear measurements of the bones of the lower limb. Biomed. Res-India, 16(2): 125-127.

24. Stolwijk N.M., J.W. Louwerens, B. Nienhuis, J. Duysens, N.L. Keijsers (2011). Plantar Pressure With and Without Custom Insoles in Patients with Common Foot Complaints. Foot Ankle Int., 32(1): 57-65.

25. Valdez D., M. B.Horodyski, M.E. Powers, M.D. Tillman, R. Siders (2004) Bilateral asymmetries in flexibility, stability, power, strength, and muscle endurance associated with preferred and nonpreferred legs. J. Athl. Train., (2004), 39 suppl. 2: 81-119.

26. WHO. 2000. Obesity: preventing and managing the global epidemic. Report of a WHO Consultation. WHO Technical Report Series 894. Geneva: World Health Organization.
27. Williams D.S., I.S. McClay, J. Hamill, T.S. Buchanan (2001) Lower extremity kinematic and kinetic differences in runners with hight and low arches. J. Appl. Biomech. 17: 153-163.

28. Wolański N. (2006) Rozwój biologiczny człowieka. Wydawnictwo Naukowe PWN, Warszawa.

29. Xiong S., R.S. Goonetilleke, C.P. Witana, T.W. Weerasinghe, E.Y.Au (2010) Foot Arch Characterization: A Review, A New Metric, and a Comparison. JAPMA, 100(1): 14-24.

\section{Received 18.10.2012 \\ Accepted 15.09.2013}

(c) University of Physical Education, Warsaw, Poland 